\title{
The Selection of Ship Type to Use Dual Fuelled or Gas Fuelled using Analytical Hierarchy Process: A Case Study of Indonesia Government
}

\author{
Beny Cahyono $^{1, a, *}$, Ahmad Baidowi ${ }^{\text {b }}$ and Syafiuddin, \\ Department of Marine Engineering, Institut Teknologi Sepuluh Nopember, Surabaya, Indonesia \\ a.benyjtsp90@gmail.com, b.ahmadbai@gmail.com,c.syafiuddinsodikin@gmail.com \\ *corresponding author
}

Keywords: $\quad$ Ship type, gas fueled, AHP model.

Abstract: Since the environment protection take into force of shipping industry, the use of gas as fuel on ship become more popular for gas fueled ship or dual fueled ship. Indonesia government took a role to protect the environment by apply the concept of green ship to use gas as fuel on ship. Supported by Indonesia as archipelago, rules and regulations and also the government policy, the use of gas as fuel will be suitable for Indonesia. The choice of an appropriate ship type as a pioneer study, to modification or new-built, is one of important issues for the government. An Analytic Hierarchy Process (AHP) model is constructed to choose the ship type. The criteria's as important factors are (A) Economy with sub-criteria's are (A1) total cost, (A2) operational cost, (A3) feasibility, (B) policy divided into three subcriteria's (B1) suitability to master transport plan, (B2) constrains, (B3) socio-political acceptance, and criteria (C) Technical that consist of (C1) capacity, (C2) technical feasibility, (C3) performance. The AHP model prefer to choose passenger /roro as the best ship type for gas fueled ship. The preference value for passenger/roro vessel is $39.3 \%$ followed by merchant ship $34.6 \%$ and Pioneer/ perintis with preference value $26.1 \%$. This result can be as references for the government to conduct a further study on gas as fuel on ship to develop a proper design while the analytical hierarchy process (AHP) model represent the most suitable ship type to conduct the related study.

\section{Introduction}

Sustainability is the issue and the crucial challenge for Indonesia related to power sector, even though Indonesia was blessed with huge of energy resources. To maintain the energy sustainability, improve and create energy autonomy is one of the solution, also need energy management through policy and new technology [1], since the transportation and industrial sectors become the highest energy costumers [2]. While Qodri et.al [3] mentioned that Indonesia ranks at 55 from 71 countries related to energy security index that consisting of five dimensions: availability, affordability, accessibility, acceptability and efficiency which means that Indonesia's energy security is less than satisfactory and it should be improved. 
Looking for Indonesia's gas industry, which has the dramatic changes during the history, the domestic demand would be doubled or tripled compare to current gas demand. To fill the gap, the policy and infrastructure of gas industry should be improved, even though Indonesia is one of the largest LNG exporters for three decades [4].

Gas as fuel become popular due to the environment issues. Many kinds of gas that could be used as fuel with different performance, and LNG is one that gives a significant improve to overall environmental performance [5], and also, LNG is proven as a commercial marine fuel [6]. Since the emission reduction technology selection has established by many researches, such as [7] which give LNG as the most suitable alternatives by using Fuzzy-MCDM method, and according to [8], LNG is the most suitable alternative fuel that was made by comparing eleven criterions.

"Tol Laut" concept is one of Indonesia government's vision and mission, Nawacita, which is to improve transportation performance, connecting the island and strengthen the nation. The concept should be supported by the energy sector, policy and also the current technology. Since the environment protection take into force of shipping industry, the use of gas as fuel on ship become more popular for gas fueled ship or dual fueled ship. Indonesia government took a role to protect the environment by apply the concept of green ship to use gas as fuel on ship. Supported by Indonesia as archipelago, rules and regulations and also the government policy, the use of gas as fuel will be suitable for Indonesia.

The green concept for maritime transport is the most suitable concept to realize Nawacita and fulfill the international requirement for environmental protection at once. Nawacita supported by many of ship types in it practice, and to get the appropriate ship type to be developed related to gas as fuel, the study was built to present and give recommendation.

\section{Analytical Hierarchy Process (AHP)}

The selection method to choose ship type that give the most suitable for dual fueled and gas fueled is Analytical Hierarchy Process (AHP). AHP is one of multi-criteria decision analysis (MCDA) that has wide range capability in maritime sector, e.g in [9] which explain the ship flag stage selection in Taiwanese ship-owner, [10] that using multi-criteria approach to choose the reference to start a new design, [11] focus on the selection process of vessels in the Norwegian maritime sector, especially in meeting present and future exhaust regulation.

Basically, AHP is general theory related to measurement. It was used to give the ratio scale from discrete or continue pairwise [12]. Analytical hierarchy process (AHP) consist of three stage, namely:

1. Decomposition

When the goal already, break down the problem into it smallest component is the next step. At this stage, the problem's level was established.

2. Pairwise comparison (comparative judgment)

Pairwise comparison is about compare of two elements for it weight for certain level. This comparison is the main point of AHP, and will influence the elements priorities. Regarding to get the best result, respondent should understand the overall compared elements. The weight score based on linguistic variables, 1 for "equally important", 3 for "weakly important", 5 for "demonstrably important", 7 for "strongly important", and 9 for "absolutely important. While value 2, 4, 6 and 8 represent the verbal judgement between the above described.

3. Synthesis from priority

Each pairwise comparison matrix should calculate the Eigen vector to produce the local priority for each level. Global priority is obtained by synthesis between local priorities. 
AHP is well established by using Consistency Ratio (CR) as it parameter. The CR should not more than 0.1, while CR described as Consistency Index (CI) divided by Random Index (RI). RI refer to table 1 below, while CI based on equation (1).

$$
C I=\frac{\lambda_{\max }-n}{n-1}
$$

Eigen factor $(\lambda)$ is obtained from average sum for each matrix row, and $\mathrm{n}$ is matrix ordo.

Table 1: Random index value

\begin{tabular}{|l|l|l|l|l|l|l|l|l|l|l|}
\hline $\mathrm{n}$ & 1 & 2 & 3 & 4 & 5 & 6 & 7 & 8 & 9 & 10 \\
\hline $\mathrm{RI}$ & 0 & 0 & 0.58 & 0.9 & 1.12 & 1.24 & 1.32 & 1.41 & 1.45 & 1.49 \\
\hline
\end{tabular}

\section{Case Study}

The goal has been set, to find the most suitable ship to implement dual fuel technology for Indonesia government. The problem will break down into criteria and sub-criteria. According to the previous study related to transportation, the using of multi-criteria decision making has widely used, and the model has been used for assessment of road transport projects [13], selection of mode of transport and vessels [14] [15] [16] [17], and for optimization [18]. The criteria and sub-criteria was used and simplified into the most studied as mention in [11]. Technical, Economic, and Policy is the three criteria used in this study, while each criteria divided into three sub-criteria.

To select the alternatives, [19] shown that Passenger ferry vessel is the highest number of operated vessel that using gas as its fuel, while Platform Supply Vessel (PSV) is the highest number of ordered vessel that using gas as its fuel, following with Ro-ro and passenger ferry. Statistically, Indonesia government has Ro-ro vessel growth from 254 to 354 unit from 2012 to 2016 [20], while the merchant ship, including general cargo, container, bulk carrier, and tanker, grows more than $100 \%$ from period 2005 to 2013, passenger vessel grows $88.6 \%$ from the mentioned period. Since Indonesia is an archipelago, the Perintis / pioneer vessel growth rapidly and expected to 198 unit at 2019 from 95 unit at 2015 [21]. 


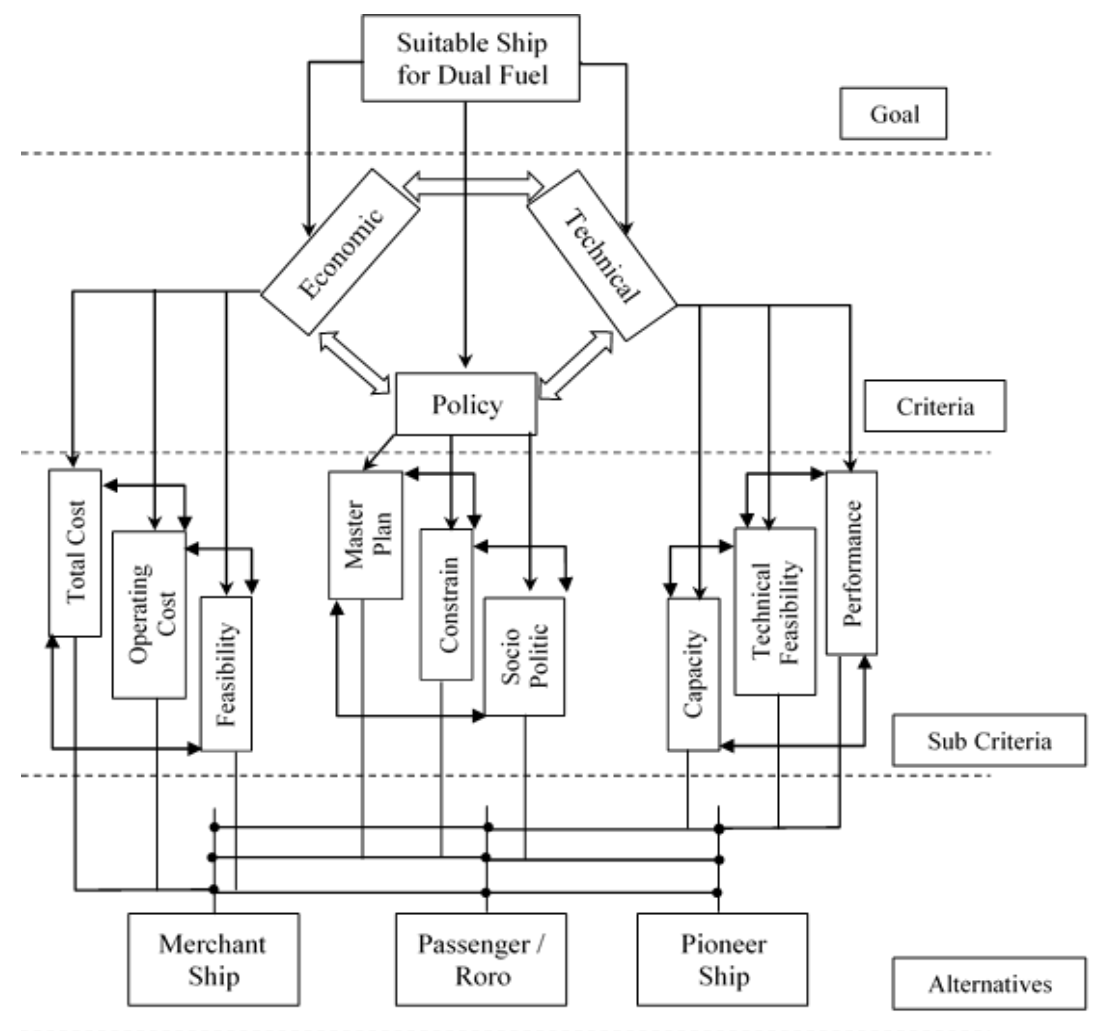

Figure 1: Hierarchy structure of ship type selection

Questionnaires were distributed that consist of pairwise comparison from each respondent. The respondents involves classification biro, academic institutional, ship-owner and operator, and other related government institution. Since these respondents have a better knowledge relating to gas fueled ship, the regulator have studied the regulation of International Code of Safety for Shipping Using Gases or Other Low-Flashpoint Fuels (IGF Code). Operator respondent has conducted the feasibility study to convert their fleet to gas fueled ship.

\section{Result and Discussion}

\subsection{Judgement and Rank}

The pairwise from each respondent has been collected and calculated using geo-mean method to get a single pairwise judgment for each level. The criteria level shown that "Technical" takes the highest place of weight, followed with "Economy" and the last "Policy" criteria, with the preference value, in order, $0.517,0.289$ and 0.195 . The pairwise also shown that at criteria level, the Consistency Ratio (CR) is 0.095 , it's mean that the judgment well accepted to the next level, the sub-criteria level. 
While the pairwise going further into sub-criteria, the local weight obtained, then the local weight also arise with other local weight. The overall judgement generate a rank for each criteria as shown below.

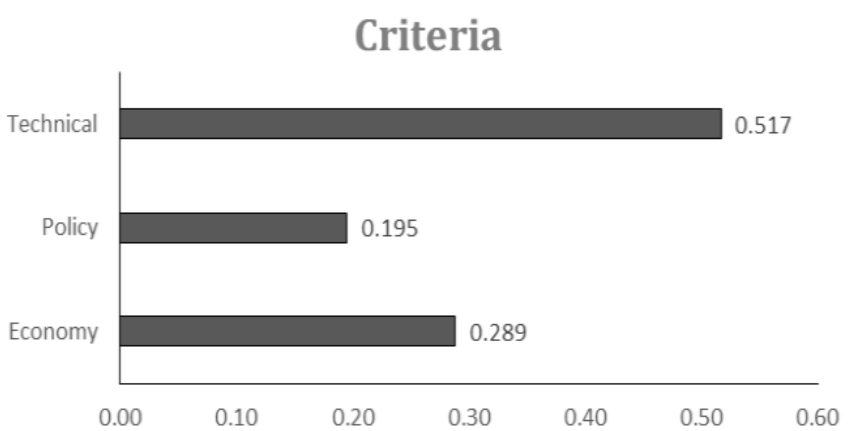

(a)

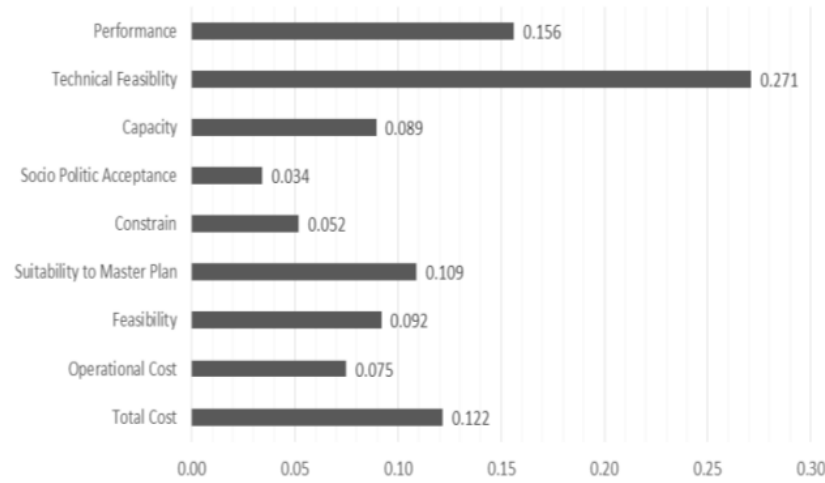

(b)

Figure 2: (a) Criteria weight (b) Sub-criteria global weight.

Global weight shown that the "Technical Feasibility' is the most important criteria to assessment the suitability for vessel type regarding to gas fueled and dual fueled, the represent value is 0.271 or about $27.1 \%$ compared from all sub-criteria. Second place for global weight is "Performance" with value 0.156 followed by "Total cost" 0.122 , "Suitability with master plan" 0.109 , "Feasibility" from "Economy" criteria with the value 0.092, "Capacity" 0.089, "Operational cost" 0.075, "Constrain" 0.052, and the last is "Socio politic acceptance" with value 0.034. Pairwise comparison for "Cost" criteria gives 0.011 of CR value, 0.018 CR for "Policy" and 0.005 CR for "Technical". The CR shown that the judgment and pairwise comparison could go further to alternatives pairwise comparison.

Pairwise comparison get into the alternatives level. Table 2 summarize the result. Passenger/roro type seem to be the most suitable vessel type for Indonesia government to develop as dual fueled and gas fueled vessel. Global weight for passenger/roro vessel is 0.393 or about $39.3 \%$ respondent likes to choose passenger/roro type as the suitable vessel to use gas as its fuel. Merchant vessel with preference value $34.6 \%$ and Perintis/pioneer about $26.10 \%$.

The score of merchant vessel for "economy" is about $0.419,0.3567$ for "Policy" and 0.3011 for "Technical". Passenger/roro gives 0.3126 point for "Economy", 0.417 for "Policy" and 0.4288 for "Technical", while Perintis/pioneer has 0.2683 point for "Economy", 0.2262 for "Policy" and 0.27 point for "Technical", and overall as mentioned above. 
Table 2: Overall weight

\begin{tabular}{|c|c|c|c|c|c|c|c|c|c|c|}
\hline \multirow[b]{2}{*}{ Criteria } & \multirow[b]{2}{*}{ Weight } & \multirow[b]{2}{*}{ Sub Criteria } & \multirow{2}{*}{$\begin{array}{c}\text { Local } \\
\text { Weight }\end{array}$} & \multirow[b]{2}{*}{ Global Weight } & \multicolumn{2}{|c|}{ Merchant Ship } & \multicolumn{2}{|c|}{ Passenger/Roro } & \multicolumn{2}{|c|}{ Pioneer } \\
\hline & & & & & $\begin{array}{c}\text { Local } \\
\text { Weight }\end{array}$ & $\begin{array}{c}\text { Global } \\
\text { Weight }\end{array}$ & $\begin{array}{c}\text { Local } \\
\text { Weight }\end{array}$ & $\begin{array}{c}\text { Global } \\
\text { Weight }\end{array}$ & $\begin{array}{c}\text { Local } \\
\text { Weight }\end{array}$ & $\begin{array}{c}\text { Global } \\
\text { Weight }\end{array}$ \\
\hline \multirow{3}{*}{ Economy } & \multirow{3}{*}{0.289} & Total Cost & 0.422 & 0.122 & 0.5084 & 0.0619 & 0.2018 & 0.0246 & 0.2898 & 0.0353 \\
\hline & & Operational Cost & 0.260 & 0.075 & 0.3146 & 0.0236 & 0.3532 & 0.0265 & 0.3322 & 0.0249 \\
\hline & & Feasibility & 0.318 & 0.092 & 0.3859 & 0.0354 & 0.4264 & 0.0392 & 0.1877 & 0.0172 \\
\hline \multirow{3}{*}{ Policy } & \multirow{3}{*}{0.195} & Suitability to Master Plan & 0.559 & 0.109 & 0.3117 & 0.0339 & 0.4535 & 0.0494 & 0.2348 & 0.0256 \\
\hline & & Constrain & 0.265 & 0.052 & 0.4681 & 0.0242 & 0.3100 & 0.0160 & 0.2219 & 0.0115 \\
\hline & & Socio Politic Acceptance & 0.176 & 0.034 & 0.3317 & 0.0114 & 0.4627 & 0.0159 & 0.2055 & 0.0070 \\
\hline \multirow{3}{*}{ Technical } & \multirow{3}{*}{0.517} & Capacity & 0.173 & 0.089 & 0.1940 & 0.0173 & 0.5777 & 0.0516 & 0.2283 & 0.0204 \\
\hline & & Technical Feasiblity & 0.525 & 0.271 & 0.2958 & 0.0802 & 0.4569 & 0.1239 & 0.2473 & 0.0670 \\
\hline & & Performance & 0.302 & 0.156 & 0.3716 & 0.0580 & 0.2951 & 0.0461 & 0.3333 & 0.0521 \\
\hline & & & & & Overall & 0.3460 & & 0.3930 & & 0.2610 \\
\hline
\end{tabular}

\subsection{Sensitivity Analysis}

Sensitivity analysis was conducted to check the flexibility of the result. Changing the weight for each criteria into different value, compare with the original weight then check the final selected alternative. Figures below shown the sensitivity analysis that vary the criteria value. Sensitivity analysis \#1 by changing the Economy, Policy and Technical criteria into value $0.25,0.25$ and 0.5 respectively. Sensitivity analysis \#2 change the value Economy into 0.25, Policy into 0.5 while Technical into 0.5, while Sensitivity analysis \#3 change the value Economy into 0.5, Policy into 0.25 and Technical value into 0.25 , in contrary, Sensitivity analysis \#4 gives Economy, Policy and Technical equal value, 0.333 represent one third value.

Sensitivity analysis shown that the origin result keep in the place, the Passenger/roro vessel as the most suitable vessel regarding to gas fueled and dual fueled. The origin value for passenger/roro vessel is $39.3 \%$, increase into $39.7 \%$ for sensitivity analysis \#1, 39.3\% at sensitivity analysis \#2 and decrease a little for sensitivity analysis \#4 at $38.6 \%$, and also the above sensitivity analysis did not change the order of alternative's weight.

Sensitivity analysis \#3 as shown in Fig. 7 the order of alternatives weight changes, the highest value for merchant ship about $37.4 \%$, following by passenger/Roro 36.8\% and perintis/pioneer ship for 25.8\%. The sensitivity analysis \#3 give a little difference between merchant ship's weight and passenger/roro's weight. The original value for merchant ship is $34.6 \%, 39.3 \%$ for passenger/roro and $26.1 \%$ for perintis/pioneer ship. It shown that the merchant ship takes more value in Economy criteria since this criteria increased into 0.5 from the origin value 0.313 .

\section{Conclusion}

The utilize gas as fuel become more popular and more environmental friendly for marine issues. Supported by huge gas resources, Indonesia should develop the technology and also exploit the use of gas as fuel. The study present the choosing process of ship type regarding to gas fueled and dual fueled vessel, that include three criteria and nine sub-criteria, facing the three alternatives. The result shown that the Passenger/roro vessel is the most suitable vessel developed for the use of gas as its fuel. 


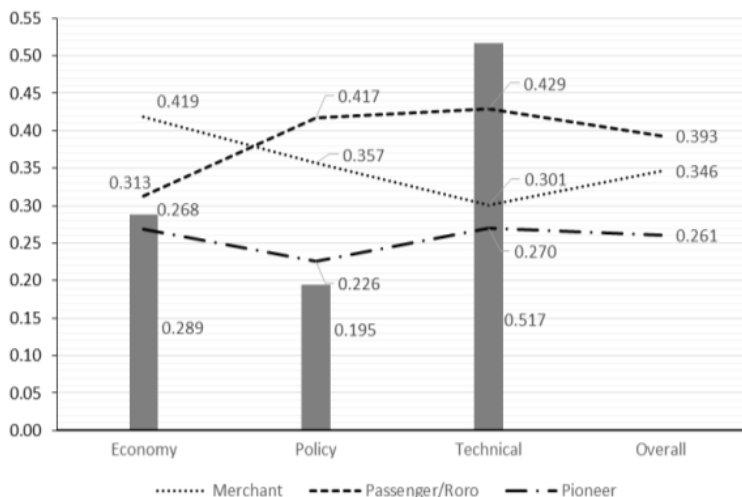

(a)

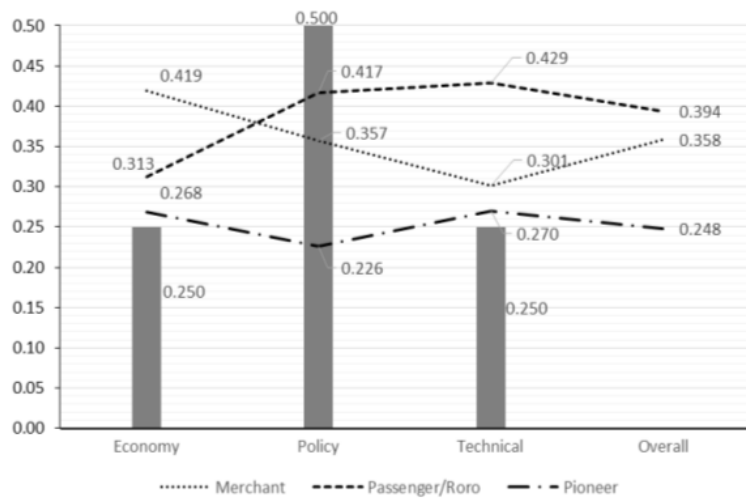

(c)

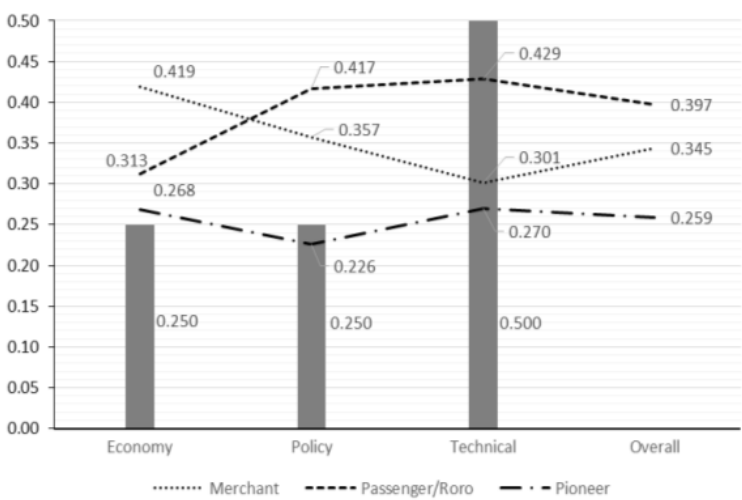

(b)

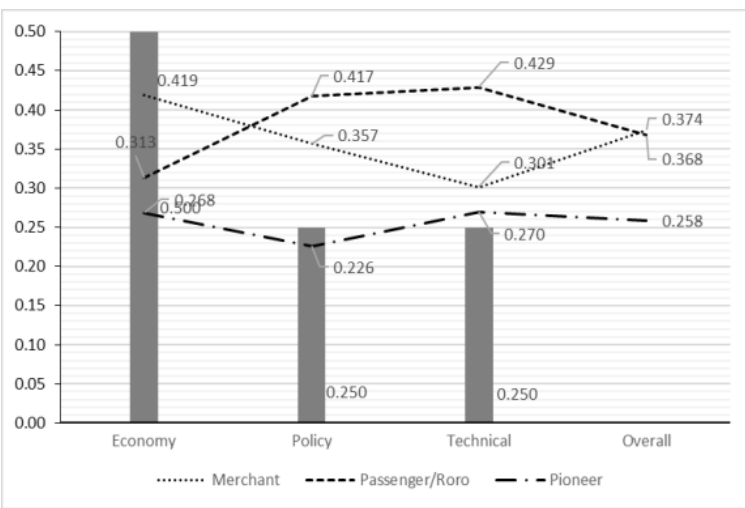

(d)

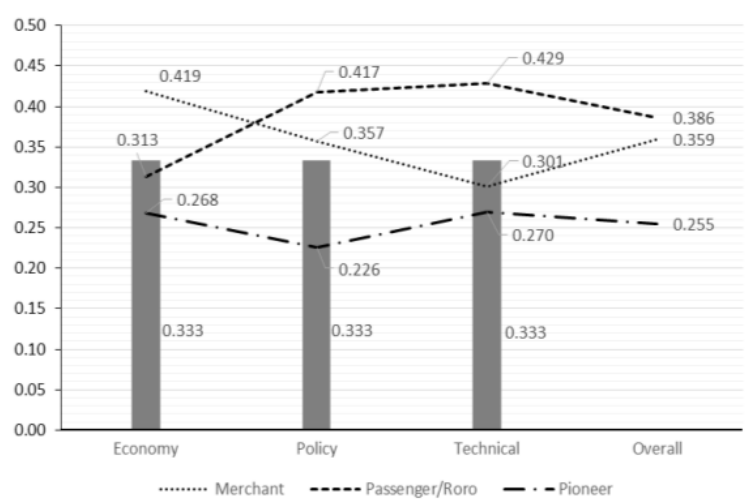

(e)

Figure 3: (a) Overall weight original (b) overall weight (sensitivity analysis \#1) (c) overall weight (sensitivity analysis \#2) (d) overall weight (sensitivity analysis \#3) (e) overall weight (sensitivity analysis \#4)

\section{References}

[1] H. H. M, I. M. T.M and N. Hadi, "A review on energy scenario and sustainable energy in Indonesia," Renewable and Sutainable Energy Reviews, vol. 16, pp. 2316-2328, 2012.

[2] M. Sugeng and T. Günter, "Secure energy supply in 2025: Indonesia's need for an energy policy strategy, "Energy Policy, vol. 61, pp. 31-41, 2013.

[3] F. E. Qodri, W. P. Widodo and S. Mahmud, "An assessment of Indonesia's energy security index and comparison with seventy countries, " energy, vol. 111, pp. 364-376, 2016.

[4] W. P. Widodo, M. Yusman, W. P. Yoga, H. Djoni, S. Harimanto and A. Rezki, "Status and oulook of natural gas industry development in Indonesia," Journal of Natural Gas Science and Engineering, vol. 29, pp. 55-65, 2016. 
[5] B. Selma, F. Erik and A. Karin, "Environmental assessment of marine fuels: liquefied natural gas, liquified biogas, methanol and bio-methanol," Journal of Cleaner Production, vol. 74, pp. 86-95, 2014.

[6] Y. Byeong-Yong, "Economic assessment of liquefied natural gas (LNG) as a marine fuel for CO2 carriers compared to marine gas oil (MGO)," Energy, vol. 121, pp. 772-780, 2017.

[7] R. Jingzheng and L. Marie, "Selection of sustainable alternative energy source for shipping: Multi-criteria decision making under incomplete information," Renewable and Sutainable Energy Reviews, vol. 74, pp. 1003-1019, 2017.

[8] D. Cengiz and Z. Burak, "Environmental and economical assessment of alternative marine fuels," Journal of Cleaner Production, vol. 113, pp. 438-449, 2016.

[9] C. C. Chou and J. F. Ding, "An AHP model for the choice of ship type flag: A case study of Taiwanese shipowners," International Journal of Maritime Engineering, vol. 158, pp. A61-A68, Jan-Mar 2016.

[10] X. Xinlian, X. Dong-Ling, Y. Jian-Bong and W. Jin, "Ship selection using a multi-criteria synthesis approach," Journal of Marine Science Technology, vol. 13, pp. 50-62, 2008.

[11] A. Guerra and M. M. Jenssen, "Multi criteria decision analysis (MCDA) in the Norwegian maritime sector," Norwegian University of Science and Technology (NTNU), Trondheim, 2014.

[12] T. L. Saaty, Decision making for leaders, Mervis Hill: University of Pittsburgh, 1990.

[13] E. E. Karsak and S. S. Ahiska, "Fuzzy multi-criteria decision making approach for transport projects evaluation in Istanbul," Computational Science and Its Application - ICCSA 2005, pp. 301-311, 2005.

[14] Z. Sener, "Evaluating ship selection criteria for maritime transportation," Journal of Advanced Management Science, vol. 4, no. 4, pp. 325-328, 2016.

[15] Z. Sener and E. Ozturk, "A QFD-based decision model for ship selection in maritime transportation," International Journal of Innovation, Management and Technology, vol. 6, no. 3, pp. 202-205, 2015.

[16] A. Mrvica, A. Jugovic and M. Kovacic, "The role and applicability of multi-criteria procedures in the function of defining the model for connecting the mainland and island and island in between," Scientific Journal of Maritime Research, vol. 29, pp. 156-164, 2015.

[17] L. Turcksin, A. Bernardini and C. Macharis, "A combined AHP-PROMETHEE approach for selecting the most appropriate policy scenario to stimulate a cleam vehicle fleet," Procedia Social and Behavioral Sciences, vol. 20, pp. 954-965, 2011.

[18] P. . R. Evangelos and S. L. Byung, "Multicriteria analysis in shipping investment evaluation," Maritime Policy \& Management, vol. 39, no. 4, pp. 423-442, 2012.

[19] DNV-GL, "LNG As Ship Fuel: The future-Today," DNV GL, Hamburg, 2014.

[20] B. K. Sumadi, Statistik Perhubungan 2016, Jakarta: kementerian Perhubungan, 2017.

[21] B. Ma'aruf, "The role of the Indonesia Hydrodynamic Laboratory to increase productivity of the national shipbuilding industry," in International Symposium on Hydrodynamics, Surabaya, 2017. 